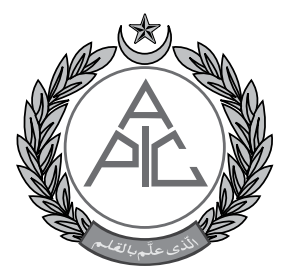

\title{
Airway management in critically sick in intensive care
}

\author{
S. K. Malhotra, MD, FICA ${ }^{1}$, Komal Gandhi ${ }^{2}$ \\ Malhotra SK, Gandhi K.
}

1'Professor, Department of
Anesthesiology, Maharishi
Markandeshwar Institute
of Medical Sciences and
Research (MMIMSR), Mullana,
Ambala-133207, (India)
'2Assistant Professor,
Department of Anesthesiology
\& Intensive Care,
The Postgraduate Institute
of Medical Education and
Research (PGIMER), Sector 12,
Chandigarh, 160012, (India)
Correspondence:
Dr. SK Malhotra, Professor
of Anesthesiology, Maharishi
Markandeshwar Institute
of Medical Sciences and
Research (MMIMSR), Mullana,
Ambala-133207, (India); E-mail:
drskmalhotra@yahoo.com
Received: 12 Sep 2018
Reviewed: 5 Oct 2018
Accepted: 10 Oct 2018

\begin{abstract}
In critically ill patients in Intensive Care Unit (ICU), patency of airway and management of difficult airway are of utmost importance. The incidence of difficult intubation may be $10 \%$ to $22 \%$ depending on the various factors in patient as well as availability of equipment facilities. As compared to the regular surgery in operation theatre, the management of airway in critically ill patients is considerably different and more challenging. The physiological reserve and co-morbidities are more common in critically ill patients. In ICU, recent techniques of airway management must be considered and practiced, such as videolaryngoscope (VLS), fiberoptic bronchoscope and supraglottic devices. The success for airway management would be greater if airway expert, the required devices and an adequate protocol are available. The outcome of managing airway would be enhanced if best use of available airway devices in a particular hospital setup since every instrument may not be available. The standard guidelines for difficult airway and the protocol of individual hospital may reduce the complications; hence must be followed. The availability of difficult airway cart and capnograph is a must. The indications and timing of surgical airway must be clear to the airway team. The Training courses for the staff in ICU should be held regularly to apprise them of advancement in airway management. The best use of available airway equipment should be made in critically ill patients. At least, one airway expert must be accessible in ICU at any given time.
\end{abstract}

Key words: Endotracheal tube; Tracheal intubation; Extubation; Tracheostomy; Supraglottic devices; Videolaryngoscope; Tube exchanger

Citation: Malhotra SK, Gandhi K. Airway management in critically sick in intensive care. Anaesth Pain \& Intensive Care 2018;22 Suppl 1:S21-S28

\section{INTRODUCTION}

Management of airway has a pivotal role in Intensive care setup. Perhaps that is the rationale that contemporary ICUs are associated or managed by the anesthesiologists in many parts of the world. The incidence of difficult airway in the ICU is $12 \%$ to $22 \%$, which is greater than that in operating rooms. ${ }^{1}$

It has been studied that $61 \%$ of patients with airway complications in ICU lead to brain damage or fatal outcome. In case of respiratory impairment or cardiovascular emergency, securing the airway is the frequently carried out procedure. It requires proficiency, skill and experience to perform urgent intubation. The safety and quality care of patient in such situation depends on efficiency of physician in airway management. The intubation scenario is much more challenging and complicated in intensive care setting than that in operating room..$^{2,3}$ The various factors being; in ICU physicians are less skilled, the general condition of patients are less optimized, less time for preparation, full stomach patients, associated trauma injuries and the unavailability of modern airway devices. These factors lead to more complications and excessive chances of failure. It has been recommended that multidisciplinary staff 


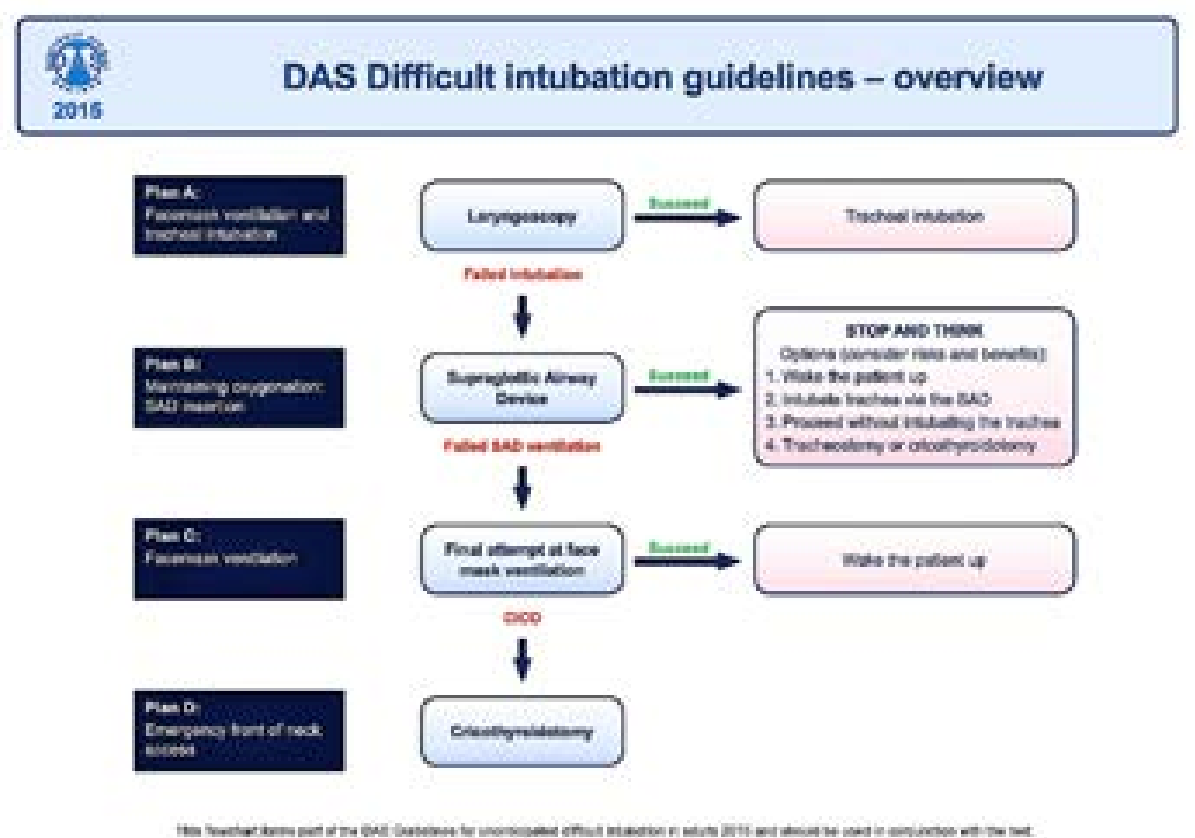

Figure 1: Difficult Intubation Guidelines 2015 (Courtesy: Difficult Airway Society) should be employed in intensive care since they may face obese and physiologically deranged patients leading to difficult airway. ${ }^{4,5}$ For successful airway management in ICU, guidelines have been published in $\mathrm{UK},{ }^{6}$ USA, Germany and Canada. (Figure 1)

It is a matter of serious consideration whether airway management algorithm suggested for anesthesia is suitable for critically ill patients in Intensive care setting. A patient with cardiorespiratory impairment needing urgent airway management is a frequent situation in ICU. If there is no skilled physician, there may be failed intubation, airway injury, airway edema and may lead to brain damage and even mortality. A 'Difficult Airway Cart" must be maintained in ICU with standard devices and equipment for airway management kept in an organized manner and layout (Box 1).

\section{EVALUATION OF THE AIRWAY}

It is a routine practice to assess airway before performing endotracheal intubation. For better reliability, it is essential to undertake a battery of airway assessment tests. Commonly performed tests include mouth opening, extension of neck, thyromental distance, short neck and Mallampati score. $^{7}$

Airway evaluation prior to tracheal intubation is the standard of care in anesthesia settings and should be routinely practiced in ICU before any tracheal intubation. Many studies about airway evaluation in controlled anesthesia settings showed that combined airway tests are better than each test alone in terms of sensitivity and reliability. Other tests recommended are Upper Lip Biting Test and body mass index.

\section{PREOXYGENATION}

It is a standard practice to undertake preoxygenation for 3-5 minutes before intubating the patient. But in patients with respiratory failure, it may not maintain sufficient oxygen saturation. In one trial, 
it was concluded that preoxygenation for 3 minutes performed by NIPPV resulted in better oxygen saturation than face mask ventilation. ${ }^{8}$ The expansion and auscultation of chest to confirm successful intubation and proper placement of tracheal tube is a standard practice. The use of a capnograph is considered much more sensitive and specific. A constant $\mathrm{EtCO}_{2}$ waveform is recommended during cardiorespiratory resuscitation. A radiographic imaging would confirm one lung intubation, if present.

\section{RAPID SEQUENCE INTUBATION}

The cardio-depressive anesthetic drugs, vasodilatation and hypovolemic shock may lead to adverse hemodynamic changes. A few cardiostable anesthetic drugs include etomidate and ketamine that maintain hemodynamics, are short acting and ideal for airway management in critically ill and hemodynamically unstable patients.

Since such patients have prolonged gastric emptying time, it is advisable to undertake rapid sequence intubation. The muscle relaxant used for this purpose is suxamethonium which is a short acting depolarizing muscle relaxant. There are controversies regarding its use as shown by various studies. ${ }^{9}$ Suxamethonium, however is avoided in case potassium levels are high, patients with burns and muscular dystrophy. Another relaxant, rocuronium may be preferred to suxamethonium in such conditions.

\section{IDEAL TECHNIQUE FOR INTUBATION}

A quality intubation procedure ensures hemodynamic stability, a proper gas exchange and least damage to nervous system. ${ }^{10}$ At least two health providers should be present to perform intubation in ICU. A preloading with $500 \mathrm{ml}$ of crystalloid is undertaken, provided there are no features of pulmonary congestion or edema. After sedation, preoxygenation using NIPPV is carried out for 3 minutes with $100 \%$ oxygen and tidal volume of $8 \mathrm{ml} / \mathrm{kg}$.

To perform a rapid sequence intubation, an intravenous anesthetic agent, either etomidate $(0.2 \mathrm{mg} / \mathrm{kg})$ or ketmaine $(1 \mathrm{mg} / \mathrm{kg})$ followed by suxamethonium $(1.5 \mathrm{mg} / \mathrm{kg})$ is generally administered, intravenously. Rocuronium is preferred if there is any contraindication of suxamethonium. To avoid regurgitation of gastric contents, cricoid pressure is applied by the assistant during intubation. The capnograph is used to confirm intubation, patient is put on ventilator with $100 \%$ oxygen in unstable patients. Since tracheal intubation is vital in unstable

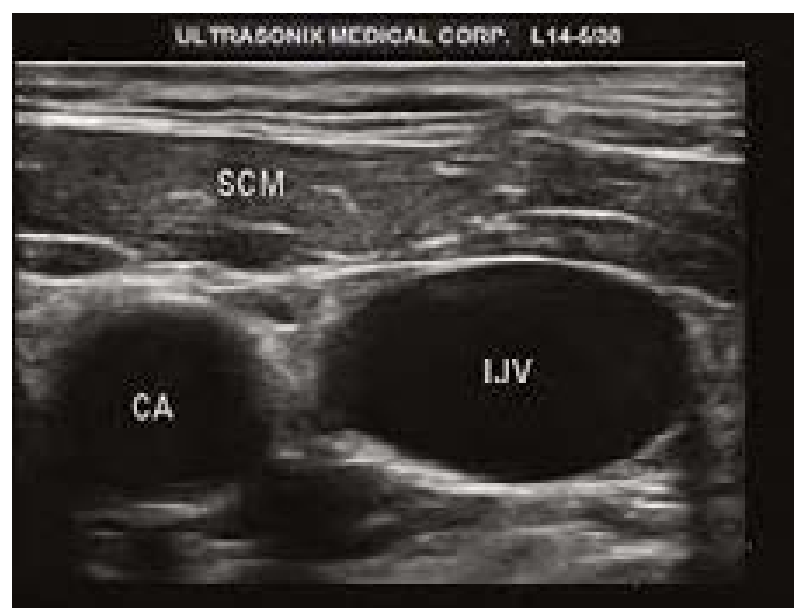

Figure 2: Ultrasound image of internal jugular vein (IJV) and carotid artery (CA)

patients, the surgical airway, such as tracheostomy must be kept ready in case tracheal intubation fails.

The chances to reintubate, either after a tryout after extubation or by extubation by accident are not uncommon. The reintubation may be challenging since the patient may be hemodynamically unstable or in hypoxia. The edema in upper airway may also complicate the reintubation.

\section{FLEXIBLE INTUBATION SCOPE IN ICU}

Earlier, the visualizing the larynx and intubating using fiberoptic bronchoscope was a routine procedure. But fiberoptic scopes are no longer popular and reusable flexible intubation scopes (FIS) have replaced them. ${ }^{11}$ FIS have a camera on the tip and uses a semiconductor technology. (Figure 2) There is provision of oxygen and suction ports. The sizes available are from 2.2 to $4.2 \mathrm{~mm}$ (external diameter).

The situations where FIS is indicated include when there is anticipation of difficult airway, such as abnormal anatomy, lesion in upper airway, fracture spine in cervical area and in nasal intubation. It can also be used in confirming the placement of tracheal tube.

There are relative contraindications for using FIS, such as secretions and hemorrhage in airway, inexperienced physician and need for urgent tracheal intubation. In case of fracture base of the skull, FIS should not be inserted nasally.

Technique for Flexible scope intubation: The appropriate selection of patient and keeping anesthetics and equipment ready is important. The route of insertion of scope is decided i.e. nasally 


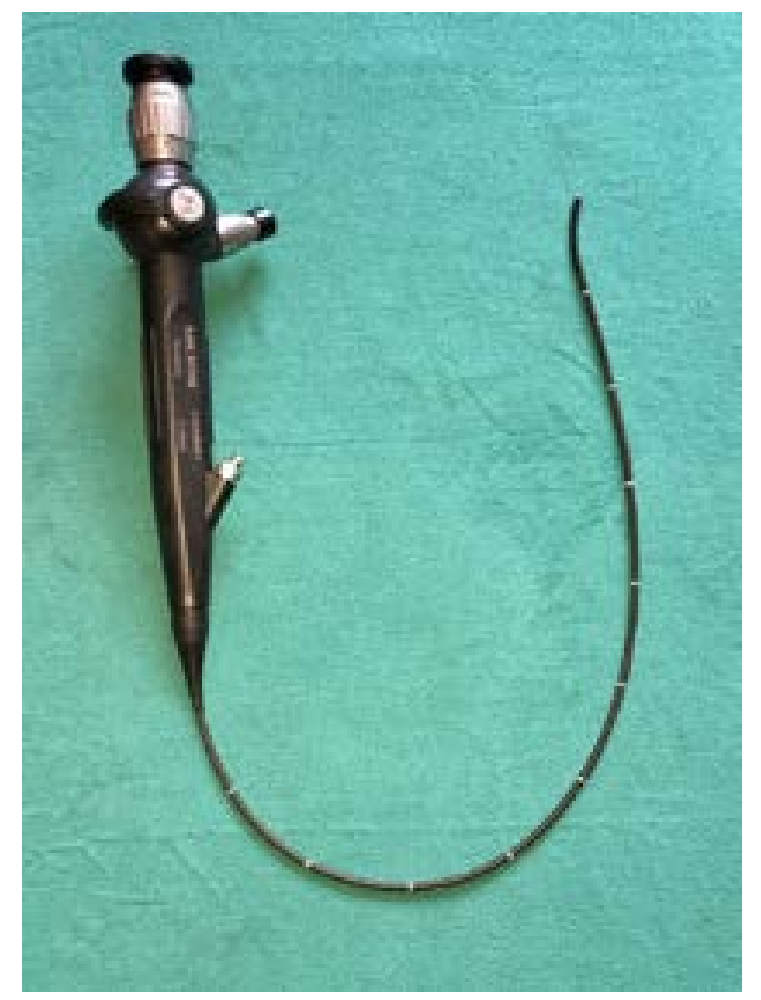

Figure 2: Flexible Intubation Scope (Carlz Storz ${ }^{\mathrm{TM}}$ )

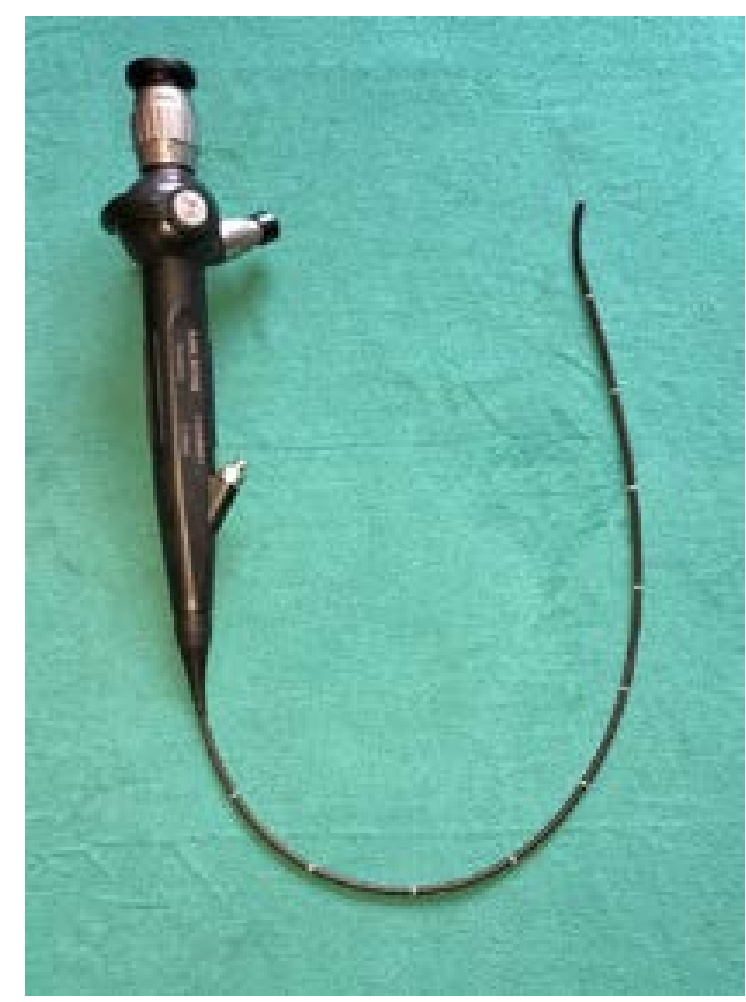

Figure 3: VLSs A: Rigid stylet (Bonfils ${ }^{\mathrm{TM}}$ ); B: Channeled VS (King Vision ${ }^{\mathrm{TM}}$ ); C: Rigid blade $\left(\mathrm{C}-\mathrm{Mac}^{\mathrm{TM}}\right.$ ) or orally. The procedure may be performed under sedation/anesthesia or in an awake patient. To reduce the secretions, glycopyrrolate $0.2 \mathrm{mg}$ is administered, intravenously. The patients with aspiration risk receive ranitidine $(50 \mathrm{mg})$ and metoclopramide (10 $\mathrm{mg}) 60$ minutes before the procedure.

For awake technique, nebulization using 4\% lignocaine or 'spray as you go' method may be employed. Various nerves, such as glossopharyngeal and superior laryngeal may also be blocked. ${ }^{12}$ For nasal route, it is recommended to instil oxymetazoline $0.05 \%$ for local vasoconstriction.

Flexible intubating scope, oral and nasal airways, face mask and tracheal tubes of appropriate size are kept ready. Commonly used route is oral. Tracheal tube is loaded to the flexible scope and bite block (e.g Williams) kept ready. Various sedatives that may be employed are, dexmedetomidine $(0.2 \mu \mathrm{g} / \mathrm{kg} / \mathrm{h})$, midazolam (1-2 mg) and infusion of remifentanil (0.05 $\mu \mathrm{g} / \mathrm{kg} / \mathrm{min}$ ). Propofol infusion is another alternative.

The successful performance using FIS needs skill and practice. A few maneuvers may help to assure the positive outcome, such as tongue pulling, thrusting the jaw, manipulating the larynx externally and using the anti-fogging jelly. ${ }^{13}$ Even after the scope has reached the carina, sometimes it is difficult to insert the tracheal tube, as it fails to negotiate at the arytenoids level. The simple way to overcome this difficulty is to rotate the tube to left by $90^{\circ}$, insert the tube for $2-3 \mathrm{~cm}$ and rotate the tube back to anatomical position. The help of videolaryngoscope may be used to insert the flexible scope which is termed as videoassisted fiberoptic intubation (VAFI).

Flexible scope is not only helpful in performing difficult intubation, it may provide diagnostic as well therapeutic utility as well. However, the learning curve is higher and needs constant practice to succeed. Occasionally, nasal injury and upper airway trauma may hamper the outcome of the procedure.

\section{VIDEOLARYNGOSCOPY FOR INTUBATION}

The technique of videolaryngoscopy (VL) provides visualization of larynx, indirectly. It may be used both for intubation in difficult situation as well assess the glottis, vocal cords and adjoining area. The view of larynx may be magnified and visualized on a monitor screen which has an extra advantage to teach the students. Though invention of VL was reported in 1940, the technique of VL is now established and included in difficult airway algorithms. It has been recommended as a first device to be used in 
anticipated difficult airway situation.

Other advantages of this tool include reduction of intubation stress response, insertion of double lumen tube ${ }^{14}$ decrease in mobility of cervical spine 15 diagnosis of laryngeal lesions, throat packing, facilitating laryngeal manipulation and decreased trauma than ordinary laryngoscope. It may also be used for the awake intubation ${ }^{16}$ and insertion of nasogastric tubes ${ }^{17}$

There are various kinds of videolaryngoscopes (VLS) available commercially. These are of various designs and sizes. A perfect VL should be easy to use, light in weight, lower learning curve, with monitor screen and with sufficient battery backup.

For retromolar intubation, rigid stylets are available in the market. The angle at distal end is 40 degree and field of vision is 110 degree. These are indicated when there is minimal mouth opening. Bonfils VLS has been widely used and studied. (Figure 3 )

For use of oral route, channelled VLs have also been used,such as King Vision ${ }^{\mathrm{TM}}$, AirTraq ${ }^{\mathrm{TM}}$ and Pentax TM.

AirTraq $^{\mathrm{TM}}$ is single-use tool and inbuilt screen at the proximal end. The tracheal tube is loaded in the side channel. These are not designed for pediatric population since the tracheal tube less than $6.5 \mathrm{~mm}$ cannot be loaded. The channelled VLs have been found to reduce mobility of cervical spine.

There are VLSs with rigid blades. These are of two kinds; standard- that are like modified Macintosh blade such as $\mathrm{C}-\mathrm{Mac}^{\mathrm{TM}}$ and the others are curved type with an angle at the distal end to increase the view angle. Common rigid VLs in market are Coopdech D-scope ${ }^{\mathrm{TM}}$, McGrath ${ }^{\mathrm{TM}}$ and GlideScope ${ }^{\mathrm{TM}} .{ }^{18}$ The differences between various rigid VLs are the shape, sizes and angulations of blade. Glidescope ${ }^{\mathrm{TM}}$ is easy to learn but is heavy as compared to C-Mac ${ }^{\mathrm{TM}}$. The time for intubation for GlideScope: 33s, CMAC: 17s, and McGarth: 41s, as revealed by a study. ${ }^{19}$

The main drawback of VL is inconsistent learning curve and problem to insert tracheal tube even when the larynx is visible. It needs practice and skill to have successful outcome. The view may also be obscured by secretions and fog on the camera. The higher cost is another factor that hinders its procurement in many hospitals, ${ }^{20}$ as revealed by a survey.

\section{SUPRAGLOTTIC AIRWAY DEVICES IN ICU}

In critical situations, the supra-glottic devices (SGADs) provide a rapid airway management, particularly the laryngeal mask airways.

Various advantages of SGADs are that they prove to be useful in a 'cannot intubate, cannot ventilate' situation, ${ }^{21}$ provide help to maintain airway during tracheostomy, help during CPR, when intubation not accessible. Moreover, they are better tolerated causing least intubation response.

On the other hand, SGADs have a few drawbacks, such as there is no surety of maintaining a perfect airway, especially if the placement is not adequate. There is no perfect seal by laryngeal mask airway cuff, so aspiration is likely to occur. ${ }^{22}$ It has been shown that intubation through intubating SGAD is up to $60 \%$, therefore, insertion of the tracheal tube is not reliable through SGAD, especially in a difficult airway. ${ }^{23}$

\section{SURGICAL AIRWAY IN ICU}

In case mechanical ventilation is required in ICU, first tracheal intubation is performed followed by tracheostomy, if ventilation is likely to be prolonged. 24

In case of long term airway the advantage of tracheostomy is better than tracheal tube since the patient may be comfortable and can move outside the ICU. The suction through tracheostomy tube is much thorough and easy. The patient is more comfortable and satisfied. The disadvantages of tracheostomy include complications related to tracheostomy tube cuff and stoma. Also there may be trauma to larynx and complications associated with mediastinum. The decannulation, if not undertaken timely may be hazardous.

The percutaneous tracheostomy may be performed instead of surgical (open) tracheostomy. (Figure 4) It

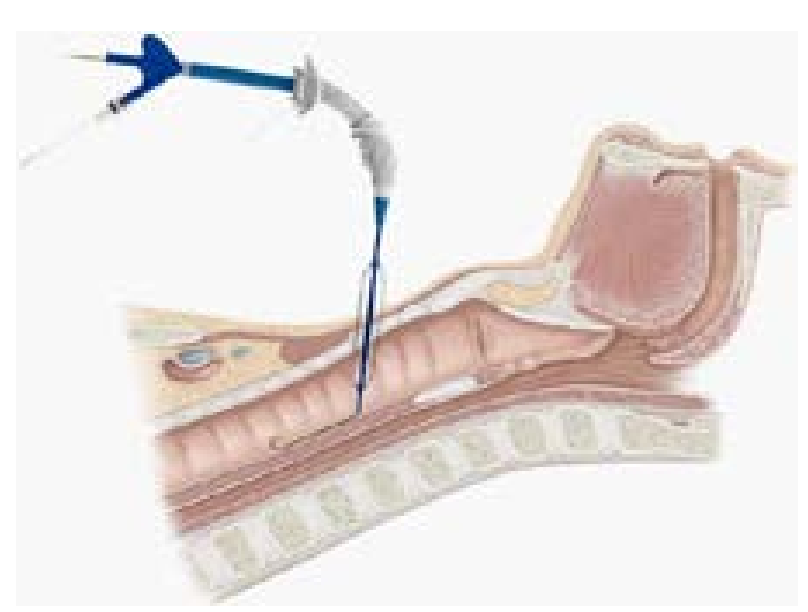

Figure 4: Blue dolphin balloon dilatation percutaneous tracheostomy (Courtesy: Cook Critical Care) 
may be performed at the bedside provided the operator has the desired skill and expertise to minimise complications. The preference of performing open or percutaneous tracheostomy depends on expertise available.

Percutaneous tracheostomy can be performed in lesser time and leads to minimal complications as compared to open tracheostomy. However, tracheal injury and perforation of posterior tracheal wall is more likely with percutaneous tracheostomy.

There are few contraindications of percutaneous tracheostomy, though these are relative. These include coagulopathy, thyroid swelling, contracture neck, short neck and age less than 15 years.

Complications of percutaneous tracheostomy may be acute or chronic.

Acute complications include partial obstruction of tracheostomy tube by posterior wall of trachea, pneumothorax or surgical emphysema. ${ }^{25}$ due to malpositioning of tube or perforation of posterior tracheal wall.

The chronic complications may include tracheal stenosis that may occur after a few weeks or months. It usually occurs above the stoma and is due to the development of granulation tissue. It may lead to high airway pressure. Management includes insertion of tracheal stent or surgical option. ${ }^{26}$ Another complication may be tracheoarterial fistula that has hazardous consequences such as substantial hemorrhage. It mostly occurs when the tube is positioned at low level. The patient may have blood in sputum and the immediate intervention in the form of surgical repair only can save the patient. ${ }^{27}$ In some patients, phonation may be reduced that may be temporary or permanent. Other complication may be trachea-esophageal fistula that may result due to prolonged intubation.

There are a few guidelines for changing the tracheostomy tube. Initially this should be changed after one to two weeks and later after two to three months. A cuff leak may be due to imperfect positioning of the tube. In case the patient has discomfort, smaller tube should be selected.

The tracheal decannulation is considered when secretions are minimal and the patient can cough effectively. The minimum cough flow should be more than $150 \mathrm{ml} /$ minute, especially if the patient has some muscular disorder. The patients with renal failure and the elderly patients may have unsuccessful decannulation.

\section{BOUGIE / TRACHEAL TUBE EXCHANGER}

The tube exchanger may be required when a tube is to be replaced by a smaller or a bigger size tube. ${ }^{28}$ The leak in the tracheal cuff also requires change of tube. Changing over to other kind of tube, such as double lumen tube also necessitate the tube exchanger.

The problems that may occur during the tube changing process may include hypoxia, esophageal intubation or the loss of airway. The tube may be changed using direct laryngoscopy with a routine laryngoscope. It may also be performed with the help of a VLS as it helps in reducing the number of attempts, avoiding the chances of esophageal intubation and severe hypoxia, thus reducing the morbidity and mortality.

\section{EXTUBATION IN ICU}

After the indication of keeping the patient intubated is over, extubation is considered. The general and specific conditions must be kept in mind before extubation. When the patient is weaned off the ventilator, a trial of extubation is given. It is a must to ensure that secretions are negligible and the laryngeal and pharyngeal reflexes are effective. Other criteria for an ideal extubation are; completely awake patient with stable hemodynamics, adequate muscle tone, very low inotropic support, $\mathrm{FiO} 2$ less than 4, absence of hypercarbia or acidosis and normal electrolytes. ${ }^{29}$ Some patients may hypoventilate with excessive secretions after extubation. Such patients may have to be re-intubated and put either on ventilator or may require non-invasive ventilation at later stage.

In a known case of difficult airway, one has to be extra cautious at the time of extubation. Such patients should be extubated with tube exchanger/bougie in situ so that re-intubation may be easier. Other devices for difficult airway should be kept ready.

After extubation, proper suctioning, nebulisation and non-invasive ventilation may be considered to maintain oxygenation.

Adequate oxygenation after extubation is maintained by oxygen therapy using Ventury mask or nasal prongs.

In a study, it was revealed that in patients who were on ventilator for 24 to 48 hours, high frequency nasal canula reduced the chances of reintubation as compared to routine oxygen therapy using low flow. ${ }^{30}$

High-flow nasal cannula (HFNC): It is indicated for oxygen therapy and is employed making use of an air/oxygen blender, nasal cannula and a humidifier. The gas that is humidified at 601 itre/min is effectively 
humidified. The advantages of this method are adequate humidification, decreased anatomical dead space and a stable $\mathrm{FiO} 2$.

This method is gaining popularity as an effective respiratory support to the patients in intensive care. In adults the results are variable as the conditions such as COPD, oxygenation before and after intubation, obstructive sleep apnea and cardiac failure affect the outcome. Nevertheless, HFNC decreases work of breathing and the respiratory rate. Some issues such as absolute indications, when to start and stop HFNC and successful timely therapy in patients with respiratory insufficiency are yet to be answered. ${ }^{31}$

\section{ROLE OF ULTRASOUND}

As compared to routine imaging procedures, ultrasound provides better information regarding the assessment of upper airway. It is portable, inexpensive and a safe bedside device with various advantages.

The various utilities of ultrasound in airway management include; to assess position of thyroid and other vessels to undertake tracheostomy, locate cricothyroid membrane, detect malpositioning of tracheal tube, assess the volume of gastic contents 32 locate the tracheal rings, assess presence of pneumothorax and placement of double-lumen tube.

\section{FUTURE PROSPECTS}

One of the various devices that are likely to be useful in future in airway management in ICU includes Virtual endoscopy (VE). This produces computer generated 2-D or 3-D images from CT scan. Virtual images created by software have excellent quality with $100 \%$ sensitivity to assess upper airway abnormalities. ${ }^{33}$ The recent use of virtual laryngoscopy is to perform upper airway assessment. The images produced are precise and comparable to fiberoptic bronchoscopy. The 3-D model is now available in the market and is useful in assessing the airway for precise management of airway in ICU. This modern technology would be of great value in airway management as it is precise and non-invasive.

\section{CONCLUSIONS}

The airway management in ICU may save a life or threaten a life. Airway patency, effective breathing and adequate gas exchange is of paramount importance in the patients admitted for intensive care. Airway management in critically ill patients in ICU is altogether different from the patients in operating room. Therefore, the physicians in ICU must be familiar with the airway devices and techniques to secure airway.

The management of airway in ICU is becoming advanced as a result of state-of-the art devices being available. The success of airway management depends on the airway physician, the equipment and the strategy to perform the procedure. Each hospital and institute should prepare its own difficult airway guidelines/protocol depending on the availability of airway equipment. It should be mandatory to have at least one trained airway provider round the clock.

Conflicts of interest: None declared by the authors.

Authors' contribution: Both authors have all equally contributed in the preparation of this manuscript.

\section{REFERENCES}

1. Jabre P, Avenel A, Combes X, Kuls$\operatorname{tad}$ E, Mazariegos I, Bertrand L, et al. Morbidity related to emergency endotracheal intubation - A substudy of the Ketamine Sedation trial. Resuscitation. 2011;82:517-22.

2. Martin LD, Mhyre JM, Shanks AM, Tremper KK, Kheterpal S. 3,423 Emergency tracheal intubations at a university hospital: airway outcomes and complications. Anesthesiology 2011; 114: 42-8.

3. Mayo PH, Hegde A, Eisen LA, Kory P, Doelken $P$. A program to improve the quality of emergency endotracheal intubation. J Intensive Care 2011;26:
50-6.

4. Law JA, Broemling N, Cooper RM, et al. The difficult airway with recommendations for management - part 2 - the anticipated difficult airway. Can J Anaesth 2013; 60: 1119-38.

5. Apfelbaum JL, Hagberg CA, Caplan $\mathrm{RA}$, et al. Practice guidelines for management of the difficult airway: an updated report by the American Society of Anesthesiologists Task Force on Management of the Difficult Airway. Anesthesiology 2013; 118: 251-70.

6. Frerk C, Mitchell VS, McNarry AF, et al. Difficult Airway Society 2015 guidelines for management of unanticipated difficult intubation in adults. $\mathrm{Br} \mathrm{J}$ Anaesth 2015; 115: 827-48.

7. McNarry AF, Patel A. The evolution of airway management - new concepts and conflicts with traditional practice. Br J Anaesth 2017;119:i154-i166.

8. Jaber S, Amraoui J, Lefrant JY, Arich $C$, Cohendy R, Landreau L, et al. Clinical practice and risk factors for immediate complications of endotracheal intubation in the intensive care unit: A prospective, multiple-center study. Crit Care Med 2006;34:2355-61.

9. Adnet F, Jouriles NJ, Le Toumelin P, Hennequin B, Taillander C, Rayeh $P$, et al. Survey of out-of-hospital emergen- 
cy intubations in the French prehospital medical system: A multicenter study. Ann Emerg Med. 1998;32:454456.

10. Griesdale DEG, Bosma TL, Kurth T, Isac G, Chittock DR. Complications of endotracheal intubation in the critically ill. Intensive Care Med. 2008;34:1835-42.

11. Hagberg C, Artime C, Daily W, Eds. A Practical Guide to the Difficult Airway. Oxford University Press, New York: 2013.

12. Kushakovskyy V. Awake fibrecapnic intubation. Anaesthesia. 2007 Jul;62(7):745.

13. Collins SR and Blank RS. Fiberoptic Intubation: An Overview and Update. Respir Care 2014;59(6):865-80. [PubMed]

14. El-Tahan M, Doyle DJ, Khidr AM, Hassieb AG. Case report: Double lumen tube insertion in a morbidly obese patient through the non-channeled blade of the King Vision ${ }^{\mathrm{TM}}$ Videolaryngoscope. F1000 Research 2014;3:129.

15. Hirabayashi $Y$, Fujita A, Seo N, Sugimoto H. A comparison of cervical spine movement during laryngoscopy using the Airtraq or Macintosh laryngoscopes. Anaesthesia 2008;63(6):635-640.

16. Shinohara $H$, Ishii $H$, Kakuyama $M$, Fukuda K. Morbidly obese patient with a huge ovarian tumor who was intubated while awake using airway scope in lateral decubitus position. Masui 2010;59:625-28.

17. Roberts JR, Halstead J. Passage of a nasogastric tube in an intubated patient facilitated by a video laryngoscope. J Emerg Med. 2011;40(3):330.
18. Siu LW, Mathieson E, Naik VN, Chandra D, Joo HS. Patient- and operator-related factors associated with successful GlideScope intubations: A prospective observational study in 742 patients. Anaesth Intensive Care 2010;38(1):70-75. [PubMed]

19. Maassen $R$, Lee $R$, Hermans $B$, Marcus $M$, van Zundert A. A comparison of three videolaryngoscopes: The Macintosh laryngoscope blade reduces, but does not replace, routine stylet use for intubation in morbidly obese patients. Anesth Analg 2009;109(5):1560-65.

20. Raja AS, Sullivan AF. Adoption of video laryngoscopy in Massachusetts emergency departments. J Emerg Med. 2012;42(2):233-237.

21. Siddiqui S, Seet E, Chan WY. The use of laryngeal mask airway Supreme $^{\mathrm{Tm}}$ in rescue airway situation in the critical care unit. Sing Med $J$ 2014;55(12):205.

22. Brimacombe $J R$, Berry $A$. The incidence of aspiration associated with the laryngeal mask airway: A metaanalysis of published literature. J Clin Anesth 995;7(4):297-305.

23. Benumof JL, et al. Laryngeal mask airway and the ASA difficult airway algorithm. Anesthesiology 1996;84(3);686-699.

24. Diehl JL, El Atrous S, Touchard D, et al. Changes in the work of breathing induced by tracheotomy in ventilatordependent patients. Am J Respir Crit Care Med 1999;159:383.

25. Fikkers BG, van Veen JA, Kooloos JG, et al. Emphysema and pneumothorax after percutaneous tracheostomy: Case reports and an anatomic study.
Chest 2004;125:1805.

26. Koitschev A, Graumueller S, Zenner $\mathrm{HP}$, et al. Tracheal stenosis and obliteration above the tracheostoma after percutaneous dilational tracheostomy. Crit Care Med 2003;31:1574.

27. Scalise P, Prunk SR, Healy D, Votto J. The incidence of tracheoarterial fistula in patients with chronic tracheostomy tubes: A retrospective study of 544 patients in a long-term care facility. Chest 2005;128:3906.

28. Benumof JL. Airway Exchange Catheters : Simple Concept, Potentially Great Danger Anesthesiology 1999;91:342-44.

29. Coplin WM, Pierson DJ, Cooley KD, et al. Implications of extubation delay in braininjured patients meeting standard weaning criteria. Am J Respir Crit Care Med 2000;161:1530.

30. Nishimura M. High- flow nasal cannula oxygen therapy in adults. J Intensive Care 2015;3:15.

31. Sitthikarnkha P, Samransamruajkit R, Prapphal N, Deerojanawong J, Sritippayawan S. High-Flow Nasal Cannula versus Conventional Oxygen Therapy in Children with Respiratory Distress. Indian J Crit Care Med. 2018; 22(5): 321-325.

32. Perlas A, Mitsakakis N, Liu L, Cino M, Haldipur N, Davis L, Cubillos J, Chan $\mathrm{V}$. Validation of a mathematical model for ultrasound assessment of gastric volume by gastroscopic examination. Anesth Analg 2013;116(2):357-363.

33. Osorio F, Perilla M, Doyle DJ, Palomo JM. Cone beam computed tomography: An innovative tool for airway assessment. Anesth Analg 2008;106(6):1803-07. 